\title{
Products Generated Knowledge (Intangible Assets) Determinants in Predicting the Bankruptcy Risk?
}

\author{
Eugenia lancu \\ Stefan cel Mare University Suceava, Romania \\ Aurel Burciu \\ Stefan cel Mare University Suceava, Romania \\ Paul Pascu \\ Stefan cel Mare University Suceava, Romania
}

\begin{abstract}
A vital activity is the issue of creating a knowledge society, which can only be solved by involving all the forces of intellectual, academic, all generators of ideas. The paper is intended as a contribution, along with attempts by other specialists in finding operational solutions and their implementation in estimating the risk of bankruptcy and predicting its occurrence so through research and development, education and innovation can bring prosperity, development sustainable and personal development of every citizen. Scientific novelty and originality of research and of the results obtained is to formulate proposals of rates in the score function of economic models to estimate the risk of bankruptcy of firms. This rate takes into account intangible assets predominant factor in the evolution of the company and the market value of the company. On the basis of an analysis made it demonstrated that score function for models Altman, Conan-Holder and Rating suffered a pretty significant change if we took into account the intangible assets of the company. Entering this rate into the mentioned models was made using expert systems and neural networks. The analysis, arguments, mathematical models, principles, goals can all be made based on the methodology of scientific research in the creation of knowledge society, scientific elaborations. The results of the work can be applied to all firms in the EU countries' national economies. The mathematical model could have other economic interpretations and therefore can be used in formulating and solving a number of problems in the national economies.
\end{abstract}

Keywords: economic model, intellectual capital, expert systems, knowledge, society, intangible assets

JEL classification: M1, M2

\section{Introduction}

Global society goes today through an "age of technology and re-engineering". This transition to an advanced technology in the modern world of business resorted to a class of resources that differentiates more than ever, large corporations in terms of competitive advantage. Any company consists of tangible and intangible assets. The biggest challenge for modern managers, today, in this respect consists of difficulties and sometimes inability to measure these intangible assets even if their contribution of their exploitation is reflected in the market value of any company. These intangible assets, mainly contributes to enhanced activity of business organizations but also to the economic growth at regional, national and even global 
level. In this regard, it needs certain methods and techniques to try measure them. Thus, based on statistical methods that use those functions trend score in determining a company's introduction of the functions we tried to score some models like Altman, Conan-Holder of a rate that incorporates intangible assets. Function score obtained was placed in an expert system (SYSEXP) with which was realized an analysis of a company for a period of ten years. The results obtained by data processing using expert system by original score function (without using the rate that comprises intangible assets) and score function using a rate which refers to intangible assets shows the importance of this resource within companies. The importance of intangible assets, in particular knowledge in a business cycle leads to increased social welfare and comfort. Imperative role in boosting economic and social welfare level is today almost universally accepted, precisely because its usefulness sparked a mass phenomenon that over the last decade has been characterized and shown statistically. The certainty of the fact that a firm is distinguished from another in the same field, with about the same number of employees is due to the intangible assets that it owns because they are difficult to imitate resources and often impossible. Some of the most valuable such assets in an organization of business knowledge, which in terms of source of origin may be generated internally using individual knowledge, talents, education, skills and creativity of people composing and relationships of them. In this context, we believe that people remain the most valuable asset in a business organization because through their knowledge, through new ideas/innovative inventions and effective decisions they increase the market value of companies.

The attention of any manager should be implemented in the current organizational context, towards management and development of the intangible heritage resources of the modern corporation (trademarks, patents, procedures, managerial, organizational routines, approaches to problems, knowledge management, knowledge of specialists etc.) but in complete harmony with the traditional tangible, because by this interaction there can be created sustainable competitive advantage in the current competitive chaos.

\section{Literature review}

Information society is defined as a society organization and at the same time a knowledge society (Drucker, 1992), at the confluence of which stands paradigm knowledge-based organization.

Since the '70s, in "Future Shock", Alvin Toffler pointed to the accelerating change in all fields of knowledge, change driven mainly by the information revolution (Tacu, 1998). In the new scene with computers connected to Internet, Intranet and Extranet we are "flooded with information, but hungry for knowledge" (Naisbitt,1982), Alvin Toffler's vision in "Future Shock" is more somber, warning him of imminent of a new "flood", this time not for water, but of information (Toffler, 1973).

Assisting management by computer activity appeared as a necessity once with the issues complicating management and owing to increased time pressure in solving these problems. To what extent managerial problem solving can take advantage of assisting Information results from the degree of structuring such problems (lancu, 2011).

In some papers (Malhotra, 2003, pp.63-126), shows that the theory and practice of business administration now has some methods / models that can be useful for measuring the stock of existing knowledge in a company; however, we believe that the assessment of this "stock" regarded as an intangible asset requires different tools and methods of measurement. 
With the development of technology occurs the so-called "smart software that uses knowledge and inference procedures to solve problems difficult enough as to require human expertise to be solved" (Feigenbaum et al., 1983). The inference is a logical operation of transition from one sentence to another and the last utterance is deducted from the first. A milestone in the development of these programs was given by the emergence of intelligent fuzzy logic founded by Zadeh (Zadeh, 1965, p.338-353); in theory and various applications gradually began to discuss fuzzy referring to systems based on fuzzy logic (and a similar influence occurred on neural networks and other algorithms in the IA). The emergence of expert systems revolutionized science. Since 1990, Martin et al. (1990) have shown that "although expert systems have proved successful in solving intractable with conventional numerical methods, their role remains limited to support functions, ......"; the conclusion provided by an ES and/or other instruments in the IA must be interpreted by human experts within a business organization.

\section{Methodology}

To achieve the objective of the proposed research we started from classical architecture expert system applied to economic issues; the classic invoked architecture was tailored by its own effort, we have built an expert system (ES) which is intended specifically for processing data/knowledge constituting entries Altman models, Conan-Holder, Rating etc.

Following issues raised on an ES architecture for economic analysis in Figure No. 1 we present the overall version of the architecture for such an ES, noting that in the analysis we include "n" economic models (type Altman, Conan-Holder and like), "n" temporary economic models (meaning the continuous updating and automatic knowledge of accounting nature that are taken from the balance sheet and other accounting documents, the update may take place at the quarter and semester) and discuss two different interfaces respectively (lancu, 2011):

- An input interface between the ES and the user through which occurs updating the carrying amounts, and thus, economic and financial situation of the company assessed;

- A presentation of conclusions interface through which the top management communicates with the ES and get successively updated values of function score results.

So, the ES created by us and based on actual data applied for a publicly traded company (graphical diagram of fig. 1 shows clearly enough working principle) during 2004-2013. The analysis conducted for this company will consider using models Altman, Conan-Holder and Rating. These models are embedded in an expert system (SYSEXP). At the same expert system models will use the same data but it will introduce a new rate in scoring position, rate which is made up of what we call intangible assets. In the latter case, however, we are able to offer aspects of novelty and / or to the development of new substantiated when applying ES models with initial rates. 
Figure 1

The general architecture of the expert system SysEXP that uses economic models Altman, Conan-Holder and Rating

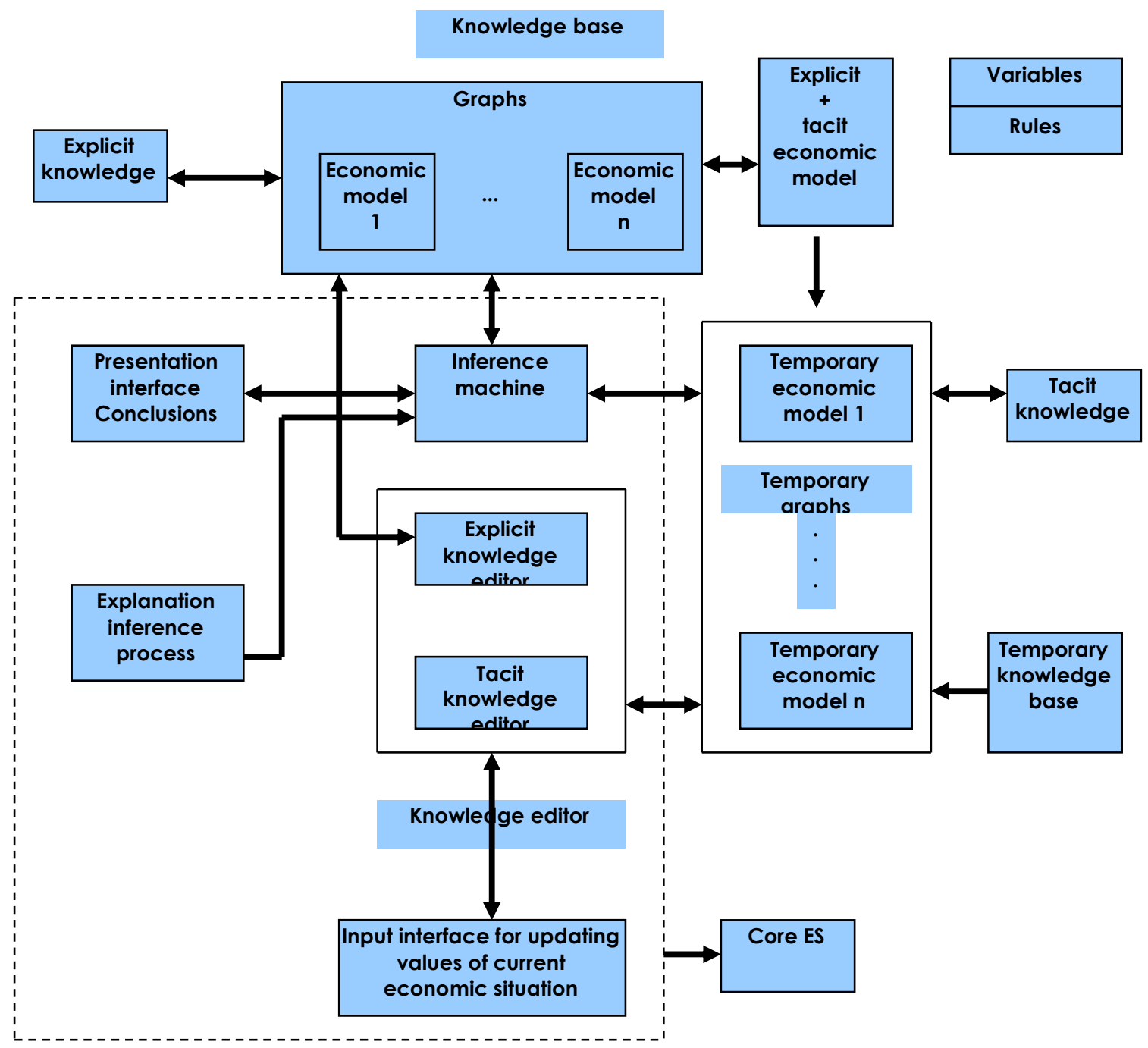

Source: lancu, E. (2011) Sisteme expert încontabilitateși Informatică degestiune, Ed. Politehnica, pg.107

The working mechanism for implementation of the ES is relatively complex and requires several intermediate steps to achieve a rate value and score function associated for each calendar year and each of the three business models (Altman Conan-Holder, Rating).

\section{Results}

Table 1 presents the value of rates calculated using SySEXP, rates that were deducted after a number of successive iterations based on the company's accounting and financial data. 
Table 1

Score function for models Altman, Conan-Holder and Rating

\begin{tabular}{c|ccc}
\hline Years & ZAltman-ES & $\begin{array}{c}\text { ZConan- } \\
\text { Holder-ES }\end{array}$ & $\begin{array}{c}\text { vRating- } \\
\text { ES }\end{array}$ \\
2004 & 2,551698 & 0,419123886 & 0,63 \\
2005 & 3,046 & 0,516942481 & 0,76 \\
2006 & 2,973 & 0,461375941 & 0,75 \\
2007 & 3,162 & 0,392049955 & 0,75 \\
2008 & 2,357 & 0,293384625 & 0,68 \\
2009 & 2,366 & 0,314275812 & 0,75 \\
2010 & 2,591 & 0,343304574 & 0,75 \\
2011 & 2,456 & 0,368729816 & 0,75 \\
2012 & 2,569 & 0,373671629 & 0,75 \\
2013 & 2,741204 & 0,393995962 & 0,75 \\
\hline
\end{tabular}

Source: Authors (based on data from www.bvb.ro and results obtained using the ES SYSEXP that used economic models Altman, Conan-Holder and Rating)

The graphical representation of the three models is represented in Figure 2.

Figure 2

Score functions represented graphically

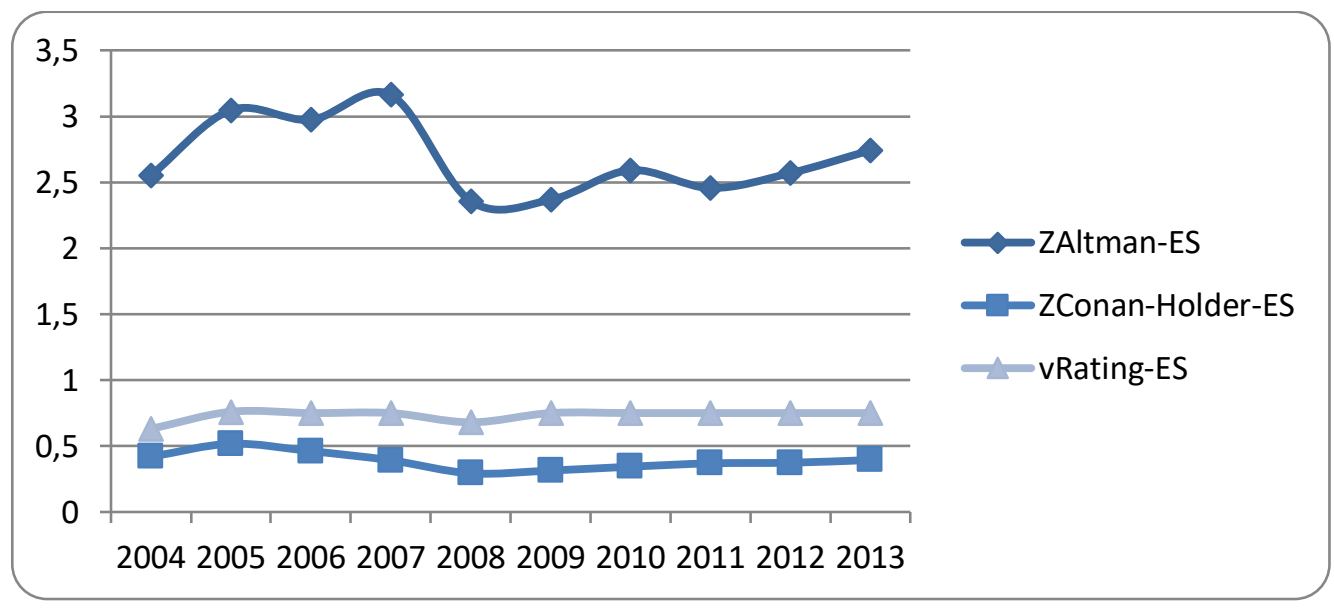

Source: Authors (based on data from www.bvb.ro and results obtained using the ES SYSEXP that used economic models Altman, Conan-Holder and Rating)

The three results automatically processed by the inference engine itself was the essential objective by the user in business practice. The trend associated with a company has always been and remains an issue of great complexity, given the large number of random factors that can influence the course of the life of the company (economic situation, various crises, market conditions, technological developments, changes in income, bankruptcy a major customer, etc.). However, while each of the three models that give content of the proposed system is based solely on the information in those accounts, showing operative form of synthetic graphics for each model Altman, Conan-Holder and the Rating becomes an invaluable aid for top management. 
Introduction in the analysis of intangible assets of the two companies

If you consider a rate that will contain intangible assets shown in the financial statements of companies analyzed by "Concessions, patents, licenses, trademarks, rights and similar assets and other intangible assets" and "Total tangible assets" rate that will be inserted in the score function in the three models described above is shown in table 2:

Table 2

The results of score function with intangible assets

\begin{tabular}{cccc}
\hline Years & $\begin{array}{c}\text { ZAltman-ES } \\
+ \\
\text { Intangible } \\
\text { (RIn) }\end{array}$ & $\begin{array}{c}\text { ZConan- } \\
\text { Holder-ES + } \\
\text { Intangible } \\
\text { (RIn) }\end{array}$ & $\begin{array}{c}\text { vRating-ES + } \\
\text { Intangible } \\
\text { (RIn) }\end{array}$ \\
2004 & 2,6473412 & 0,5147671 & 0,725643214 \\
2005 & 3,1784671 & 0,649409619 & 0,892467139 \\
2006 & 3,8075073 & 1,295883251 & 1,58450731 \\
2007 & 3,9091021 & 1,139152074 & 1,497102119 \\
2008 & 2,690451 & 0,62683561 & 1,013450985 \\
2009 & 2,6676138 & 0,615889617 & 1,051613805 \\
2010 & 3,3885022 & 1,140806811 & 1,547502237 \\
2011 & 3,0246633 & 0,937393095 & 1,318663279 \\
2012 & 3,2648836 & 1,069555207 & 1,445883578 \\
2013 & 3,3577821 & 1,010573753 & 1,366577791 \\
\hline
\end{tabular}

Source: Authors (based on data from www.bvb.ro and results obtained using the ES SYSEXP that used economic models Altman, Conan-Holder and Rating that had incorporated in score function the rate containing intangible assets)

The graph attached to these score functions is shown in Figure 3.

Figure 3

The graph of score function score for economic models that added the rate regarding intangible assets

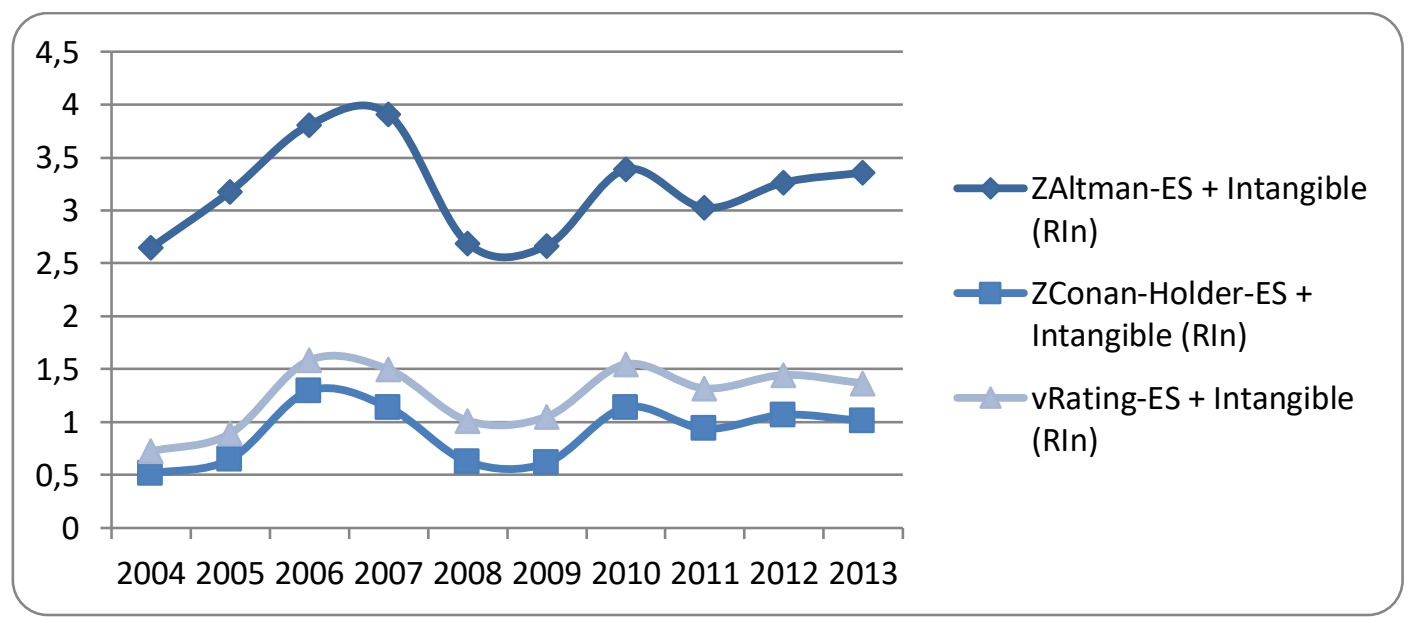

Source: Authors(based on data from www.bvb.roand results obtained using the ES SYSEXP that used economic models Altman, Conan-Holder and Rating that had incorporated in score function the rate containing intangible assets) 


\section{Discussion}

From the point of view of the ES used by us, we conducted a relatively exhaustive analysis on the company's past and present during the period (2004-2013) from the point of view of the ES based on the score functions Altman, Conan-Holder and Rating.

The same comprehensive analysis was conducted on the company using in the functions score of the same models a rate defined which consists of intangible assets (rate consists of the ratio of "Concessions, patents, licenses, trademarks, rights and similar assets and other intangible assets" and "total tangible assets").

Among other issues, we believe that it must be concluded that the intangible assets of a company can and should be entered into the equation for estimating risk of bankruptcy whether it avails to the ES or not to solve this problem (the values of bankruptcy score and the graphical form of the functions differ majorly when included in the analysis the RIn rate which takes into account intangibles firms).

\section{Conclusion}

The results obtained using the ES shows that this type of application is an appropriate tool as a method scientifically to solve other economic problems and / or decisionfacing decision makers in companies (in the most general this technology supports substantiation of economic decision-making processes).

Both the ES appeal and if the appeal to other applications using artificial intelligence techniques require a large number of years to study past founded a company, which means a lot of financial-accounting data; the higher the volume of statistics which researcher use, the more relevant final results will be to estimate the trend of and rationale for decisions on the future of an organization. From this point of view we conclude that particular Al techniques facilitate rapid processing of large volumes of statistics, updating them over time and provides operative results as a score or value summary chart (once the concept software computer type ES it is able to improve its performance such as human decision-maker will update annual data, rates and values underlying models Altman, Conan-Holder and Rating).

We appreciate that applied research provides scientifically based conclusions on the appropriateness of using various techniques to study ES type and trend of an organization and the importance of intangibles in the development and market value thereof; the same research leads us to conclude that such tools have become very commonly used in modern management as they provide clear support for a comparative analysis of various variants of a trend followed by a company within " $n$ " years. Subsequently, based on comparative analyzes of this type and on appeal to the experience and intuition of available human expert it can be shapes a credible model and, based on this model it can be projected the future course of a business organization.

From the perspective of top management, the graphic form of the results provided by the inference engine, the results provided by the very expert system that takes into account the score function of economic models that will include intangible assets presents a major role whereas, on this basis, superior decision maker can realistically foreshadow the company's future for the next years

\section{References}

1. Altman, E. I. (1968), "Financial Ratios, Discriminant Analysis and the Prediction of Corporate Bankruptcy", The Journal of Finance,Vol. XXIII, No. 4, 1968, available at: http://onlinelibrary.wiley.com/doi/10.1111/j.1540-6261.1968.tb00843.x/pdf (2/3/2016) 
2. Buchurest Stock Exchange.Main page.Available at: http://www.bvb.ro/ (2/3/2016)

3. Conan J., Holder M., (1979), "Variables explicatives de performance et controle de gestion dans lesP.M.I.", These d'Etat, CERG, Universite ParisDauphine

4. Drucker, P. (1992), "The New Society of Organizations"; Harvard Business Review

5. Feigenbaum E.,McCorduck, P, (1983), "The Fifth Generation", Addison Wesley, Reading Massachusetts

6. Iancu, E. (2011),"Sisteme expert încontabilitatesiinformatica de gestiune", Ed. Politehnica Timisoara

7. Malhotra, Y. (2003),"Measuring National Knowledge Assets of a Nation; Knowledge Systems for Development". În Report of the Ad Hoc Expert Group Meeting on Knowledge Systems for Development, 4-5 September 2003, United Nations, New York

8. Martin, T., Kivinen, J. (1990), "Appropriate Automation Integrating Human, Organization and Culture Factors". In: Preprints IFAC $11^{\text {th }}$ World Congress, vol. 1, pp.47-6

9. Naisbitt J. (1982), "Megatrends. Ten new directions transforming our lives", Warner Books

10. Tacu. Al.P. (1998),"Inteligențaartificială", Ed. Economică, Bucureşti

11. Toffler, A. (1973), "Şoculviitorului", EdituraPolitică, Bucureşti

12. Zadeh, L.A. (1965),"Fuzzy Sets", Information and Control, p.338-353

\section{About the authors}

Eugenia lancu is Associate Professor PhD at University Stefan cel Mare Suceava, Romania, Faculty of Economics and Public Administration. Has a 20 years' experience in research and teaching activities in the field of higher education. She is also author and co-author of 6 books, over 45 studies and scientific papers published in the country and abroad, indexed in international data base, being, at the same time, member in national and international associations. Areas of interest are Computer science, artificial intelligence, databases, neural networks, informatics systems design in business administration, economic informatics and mathematics, information technology management. The author can be contacted at eiancu@seap.usv.ro; eiancu56@yahoo.it.

Aurel Burciu Ph. D., is a full teacher at "Stefan cel Mare" University of Suceava, Romania, Faculty of Economics and Public Administration. He's major area of interest are Management, Comparative Management and International Business. He teaches Management at undergraduate programs and Comparative Management on Master programs. He is a Ph.D. supervisor on Business Administration. During 20022003 academic years he was a Fulbright scholar at University of Central Florida. He has published more than 10 books and 60 papers and studies on Management and Business Administration. The author can be contacted at aurelb@usv.ro.

Paul Pascu Lector Ph.D. at "Stefan cel Mare" University of Suceava, Romania, Faculty of Economics and Public Administration. He's major area of interest are Computer science, databases, informatics systems design in business administration, economic informatics and mathematics. Has a 15 years' experience in research and teaching activities in the field of higher education. She is also author and co-author of 3 books, over 30 studies and scientific papers published in the country and abroad, indexed in international data base, being, at the same time, member in national and international associations. The author can be contacted at paulp@seap.usv.ro. 